\title{
DEMOCRACIA SINDICAL NO SETOR PÚBLICO: HISTÓRIA E PERSPECTIVA
}

\author{
Antônio Warner Lucas Alves ${ }^{1}$
}

RESUMO: Além do resgate histórico do sindicalismo no setor público brasileiro, este trabalho faz um diagnóstico da sua realidade à luz da democracia sindical, discorrendo sobre teorias e conceitos relacionados ao tema. Descreve a atuação dos sindicatos dos servidores na fase da redemocratização, perante a ditadura militar, e analisa o cenário político mais recente. Para alcançar seus objetivos, faz uso de pesquisa básica estratégica, descritiva e exploratória, sob o método dedutivo, com abordagem qualitativa, com procedimentos bibliográficos e documentais, análises estatísticas secundárias de material publicado na imprensa. Por fim, restam satisfeitos os objetivos, indicando quão sensível é o movimento sindical do setor público à democracia sindical para que cumpra o seu papel junto às suas bases e nas questões sociais mais amplas; bem como outros aspectos correlatos a este estudo.

Palavras-chave: Sindicalismo. Setor público. Servidor público. Sindicato estatal.

ABSTRACT: In addition to the historical rescue of unionism in the Brazilian public sector, this work makes a diagnosis of its reality in the light of union democracy, discussing theories and concepts related to the theme. It describes the actions of the civil servants' unions in the redemocratization phase, before the military dictatorship, and analyzes the most recent political scenario. To achieve its objectives, it makes use of basic strategic, descriptive and exploratory research, under the deductive method, with a qualitative approach, with bibliographic and documentary procedures, secondary statistical analyses of material published in the press. Finally, the objectives remain satisfied, indicating how sensitive the public sector trade union movement is to trade union democracy in order to fulfill its role with its bases and on broader social issues; as well as other aspects related to this study.

Keywords: Unionism. Public sector. Public worker. State union.

\footnotetext{
${ }^{1}$ Universidade Federal da Integração Latino-Americana - UNILA. E-mail: warner.lucas@unila.edu.br.
} 


\section{INTRODUÇÃO}

O sindicalismo no setor público brasileiro se desenvolve secundariamente, tanto no campo prático como no campo acadêmico, comparativamente com o sindicalismo celetista. No campo prático, ele surge muitos anos depois do movimento dos trabalhadores celetistas. Por isso, pode-se dizer que ele é derivado do sindicalismo no sentido lato, cuja trajetória ocorre diante de impedimentos e permissões legais, à mercê das conjunturas políticas e econômicas, desde um tempo não muito distante. No campo acadêmico, ainda carece muito de historiografia, de conceitos e teorias. Mas de fato, trata-se de um fenômeno social importantíssimo que deve ser estudado e que tem muito a ser pesquisado para a sua acomodação epistemológica.

Por essa razão, o escopo deste trabalho consiste em pesquisar o que há de historiografia sobre o sindicalismo no setor público, bem como fazer um diagnóstico da sua realidade, com ênfase na autonomia e democracia sindical, no que se refere aos trabalhadores, sindicalizados ou não. Espera-se que essa trilha historiográfica possibilite analisar a atuação do movimento sindical do setor público brasileiro, no processo da redemocratização e perante a crise atual brasileira.

Para isso, discorre sobre as principais teorias e conceitos relacionados ao sindicalismo, à democracia sindical, liberdade e autonomia sindical, negociação coletiva e greve, no setor público federal; faz uma rápida demonstração da evolução histórica da atuação sindical, desde sua ilegalidade e criminalização até o momento em que ela ganha status de garantia constitucional e direito fundamental, sob a perspectiva democrática; descreve a atuação dos sindicatos dos servidores na fase da redemocratização, perante a ditadura militar brasileira; analisa a conjuntura do cenário político mais recente e indica perspectivas para o movimento sindical em estudo .

Para alcançar esses objetivos, realiza-se uma pesquisa de finalidade básica estratégica, objetivo descritivo e exploratório, sob o método dedutivo, com abordagem qualitativa e realizada com procedimentos bibliográficos, documentais, análises estatísticas secundárias e material publicado na imprensa.

Dessa forma, pretende-se contribuir academicamente condensando os principais registros que interferiram nas evoluções no sindicalismo do setor público brasileiro.

\section{Sindicalismo no setor público: uma breve revisão teórica}

Os sindicatos são associações representativas dos trabalhadores de uma categoria profissional, "visando tratar de problemas coletivos das respectivas bases 
representadas defendendo seus interesses trabalhistas e conexos, com o objetivo de lhes alcançar melhores condições de labor e vida" (DELGADO, 20II, p. 70).

Nogueira (2005, p. 42) recorre a Dahrendorf (1982) para analisar a função sindical nas relações de trabalho, ao inferir que o:

sindicalismo aproxima-se da noção de grupo de interesse particular, que desenvolve sua ação em um ambiente de conflito com os demais grupos de interesses em uma esfera limitada do ponto de vista social, tendendo a buscar convergências e uma situação de equilíbrio de modo a administrar ou institucionalizar o próprio conflito.

Essa função abordada por Nogueira (2005) deixa evidente a posição da organização dos trabalhadores diante da divisão das classes sociais na gestão dos conflitos nas relações de trabalho, cujo desfecho pode ser convergente ou de acirramento do conflito. Essa divisão de classes se dá devido à divergência dos respectivos interesses, denotando o poder de mobilização e, portanto, de barganha, de um lado, e o poder de decisão, de outro.

Quanto à classificação dos sindicatos, a doutrina clássica, segundo Arouca (2019, p. 97) estabelece alguns critérios. Ele cita Guilhermo Cabanellas (1959, p. 257258) que distingue:

a) o sindicalismo revolucionário, defendido pelos anarquistas, anarcossindicalistas, para os quais toda ação deve voltar-se contra o Estado: b) o sindicalismo reformista, que se opõe a ação violenta e direta do proletariado, entendendo, porém, que o sindicato constitui um meio de luta, devendo conduzi-la para atendimento de suas reivindicações, sem com isto atingir a sociedade; c) sindicalismo cristão, inspirado na Encíclica Rerum Novarum de Leão XIII, pregando a colaboração social de forma ampla; d) o sindicalismo comunista, que utiliza a força sindical para a implantação de seus ideais; e) o sindicalismo de Estado ou nacionalista, que pretende manter-se num campo puramente sindical.

$\mathrm{O}$ anarcossindicalismo chegou no Brasil por intermédio dos imigrantes europeus, no final do século XIX e início do século XX, cujo propósito de sociedade ideal era a que não houvesse governo, não houvesse lei, nem dinheiro, nem prisões, ou seja, uma nação sem restrições e com garantias de autonomia plena das pessoas e das comunidades. O reformista ou amarelo, antagônico ao revolucionário, condiciona suas ações às reivindicações por melhores condições de vida, de trabalho e deixam de lado as lutas políticas, revolucionárias e emancipatórias. $O$ cristão, como o próprio nome sugere, tem forte conotação religiosa e parte do princípio de cenário ideal em que patrões e empregados se organizem harmoniosamente, de acordo com valores cristãos. O comunista, com base marxista, adota a dicotomia capital-trabalho para identificar as classes sociais e suas lutas constantes no mundo do trabalho, bem como organizar a sociedade para que o capitalismo fosse substituído pelo socialismo. E, por fim, o de Estado ou nacionalista ou corporativista, cujas denominações decorrem da sua identificação tutela pelo Estado, conforme depreende Boito Jr (I991, p. 13) como sendo uma corrente ideológica que adota eficientes "mecanismos desorganizadores, na 
medida em que induz todas as correntes sindicais nacionalmente representativas a aderirem ao sindicato oficial e a aspirarem, mesmo quando no plano do discurso afirmam o contrário, a tutela do Estado sobre a organização do Estado".

No campo sociológico, o sindicalismo é compreendido como uma organização de classes. Sendo que os servidores públicos, "a exemplo do ocorrido com os operários, bem como as classes médias podem ou não buscar identidades com os demais trabalhadores em diversos movimentos políticos e sociais" (NOGUEIRA, 2005, p. 48).

Para seus estudos, Mascarenhas (2000, pp. 43-5I) situa as classes médias num "agrupamento intermediário da estrutura social, ou seja, aqueles que não se encontram nos extremos da dicotomia da sociedade capitalista: operário, de um lado, e capitalistas, de outro". A autora entende ideal situar a categoria dos servidores públicos na "estrutura social", indo além do conceito de classes médias sugerido por Nogueira (1998), sem, no entanto, abandoná-lo como ponto de referência, uma vez que esses trabalhadores estão inseridos no agrupamento que representa os setores de serviços, "integrados ao processo de produção como mão-de-obra assalariada, despossuídos dos meios de produção, explorados através da apropriação de seu sobretrabalho $e$ portadores das funções de coordenação e organização da divisão do trabalho". Essa autora assevera ainda que uma classe não é apenas a que está inserida no processo produtivo. Ela "se constitui, também, por meio das lutas travadas, das experiências vividas, e o seu reconhecimento passa, necessariamente, por sua prática política".

$\mathrm{Na}$ perspectiva socioeconômica, Arnaldo Nogueira (2005, p. 59) se refere a King (1988, pp. 53-76) para associar o movimento sindical do setor público ao Estado de bem-estar, atribuindo aos servidores o interesse "pela manutenção de seus empregos e salários e por uma certa solidariedade salarial e de classe com os demais trabalhadores", tornando irrefutável a ideia de que os servidores públicos, tanto por meio dos sindicatos quanto pela formulação de políticas públicas, podem assumir "compromissos com as políticas e instituições de Estado do bem-estar social" .

Para Nogueira (2005, p. 177), os servidores públicos são "categorias assalariadas" lotadas nos órgãos dos poderes Legislativo, Judiciário e Executivo, definidos em três grupos: trabalhadores da administração direta, trabalhadores "em atividades não exclusivas do Estado", e os empregados "nas empresas estatais".

Quanto ao trabalho profissional do servidor, Conceição (2008) define como sendo "aquele exercido de maneira habitual em benefício de outrem, mediante uma contrapartida".

Poulantzas, ao negar "um papel de força social independente ou com poder próprio" aos trabalhadores públicos, reconhece a especificidade da categoria e atribui "certa autonomia relativa (a autonomia relativa ao Estado) e uma unidade própria de interesses" (NOGUEIRA, 2005, p. 75).

Esse campo teórico é amplo e pouco explorado. Segundo Sidnei Jard da Silva (2015, p. 34), a literatura acadêmica tem privilegiado, ao longo do tempo, estudos do 
movimento sindical e das relações industriais, em função da sua relação com as forças produtivas, não ocorrendo a mesma dedicação aos estudos das relações de trabalho no setor público.

Em parte, este interesse preferencial dos pesquisadores pela prática sindical do setor privado é explicado pelo próprio papel de vanguarda exercido pelo operariado no processo de reorganização sindical no final da década de 1970, particularmente na constituição do chamado Novo Sindicalismo”. (SILVA, 2015, p. 34)

Ao chamar a atenção para a ausência na literatura acadêmica de estudos sobre sindicalismo no setor público, Silva expõe o Estado como gestor do sistema de relações de trabalho em dois segmentos que ele denomina de setor público e de setor produtivo estatal. Diante disso, o autor esclarece que é na administração direta e indireta que se encontra "o setor público propriamente dito", e é nas empresas estatais que se encontra o "setor produtivo estatal". Estes dois segmentos, historicamente, têm

formas bastantes distintas de organização e mobilização. A primeira importante diferença a ser destacada refere-se à própria organização sindical: enquanto no setor produtivo estatal os trabalhadores estão organizados em sindicatos de acordo com estrutura sindical corporativa, regida pela Consolidação das Leis do Trabalho - CLT -, no serviço público a associação sindical foi proibida por mais de meio século, mais precisamente, até a promulgação da Constituição de 1988. Portanto, um dos primeiros pontos a ser reconhecido, quando falamos do sindicalismo no setor público, refere-se à própria origem distinta da organização sindical no serviço público e no setor produtivo estatal, ainda que, em sentido abrangente, os trabalhadores do setor público estejam subordinados a um único empregador: o Estado (SILVA, 2015, p. 35).

Para este autor ainda há um vácuo acadêmico neste campo teórico, que se torna um desafio, que é "abordar conjuntamente estes 'dois campos' do sindicalismo no Estado" (SILVA, 2105, p. 34).

Há pensadores que, como Arnaldo Nogueira (1998, p. 5), atribuem a essas lacunas de estudos, arquétipos e paradigmas das relações de trabalho do serviço público, pelo fato do servidor público não ser dotado

dos mesmos parâmetros econômicos válidos para os demais assalariados no sistema de produção de mercadorias e de valor, cuja variação dos salários, da jornada ou do ritmo de trabalho, da intensidade tecnológica em relação a da quantidade de força de trabalho, estabelecem relação direta com a produtividade e os lucros. Essa ausência e as características do processo de trabalho em serviços mais individualizado e simbólico condicionam os problemas de organização coletiva ou sindical.

Essa relação produtividade-lucro ou trabalho-capital, típica do campo privado não se aplica ao setor público por questões óbvias de finalidade, pois o resultado esperado dos serviços consiste na forma e na qualidade das políticas públicas que estão 
sendo disponibilizadas para a população (diretamente) e para os meios de produção (direta e indiretamente).

Movimentos trabalhistas dos servidores públicos, sindicatos e democracia: uma breve revisão histórica

As associações mutualistas, por muito tempo, tiveram a finalidade de proteger os trabalhadores e suas famílias nos "momentos de afastamento do trabalho por acidente, viuvez, funerais etc." (MATTOS, 2009, p. 47). Além disso, tinham também o caráter recreativo e de representatividade da categoria. Até a Constituição de 1988, os trabalhadores do setor público se organizavam por meio dessas associações, devido ao impedimento legal do sindicalismo do funcionalismo público, "enquanto para o conjunto da classe trabalhadora é criado o sindicalismo oficial de Estado cuja trajetória varia entre períodos de maior e menor controle político da ação sindical" (NOGUEIRA, 1999, p. 2).

Em 1930, foi criado, em São Paulo, o Centro do Professorado Paulista; em 1931, a Associação dos Funcionários Públicos de São Paulo; em 1945, a Associação dos Professores do Ensino Secundário; em 1949, a Associação dos Professores do Ensino Oficial do Estado de São Paulo (Apeoesp); em 1952 foram criadas a Confederação dos Servidores Públicos do Brasil e a União Nacional dos Servidores Públicos (fechadas em 1964) (NOGUEIRA, 2005, p. 99; BOSCHI, 1987, apud GUEDES, 1994, p. 409; RODRIGUES, I98I, pp. 54I-550, apud NOGUEIRA, 2005, p. I04; FARIA, 2013, p. 2).

Porém, o golpe de 1964 interrompeu esse crescimento das organizações e das mobilizações das categorias do serviço público. Apenas nos anos de 1978 e 1979 é que o movimento sindical ressurge, e com ele, o movimento dos trabalhadores do setor público organiza-se e trava lutas quase sempre acompanhadas "por longas greves, resultando num total de jornadas perdidas superior às computadas no setor privado no mesmo período" (FARIA, 2013, p. I).

Nesse período foi fundado o Centro Estadual dos Professores do Rio de Janeiro, a Associação dos Professores do Estado de São Paulo e a União dos Trabalhadores do Ensino em Minas Gerais, que deflagraram as greves, que foram generalizadas em nível nacional (GUEDES, 1994, p. 410).

No âmbito das universidades federais, foi criada em 1978, a Federação das Associações de Servidores das Universidades Brasileiras - FASUBRA², e a ANDESSN, em 198I como Associação Nacional dos Docentes do Ensino Superior, e depois da $\mathrm{CF} / 88$ passou à denominação Sindicato Nacional dos Docentes das Instituições de Ensino Superior ${ }^{3}$.

\footnotetext{
${ }^{2}$ Disponível em: http://fasubra.org.br/wp-content/uploads/2016/ı/revista_fasubra.pdf

${ }_{3}^{3}$ Disponível em: http://portal.andes.org.br/imprensa/migracao/historia.html.
} 
Diante desse movimento com demonstrações de notável capacidade de reorganização política e social, o governo não deixa por menos e intervém com sérias medidas restritivas legais para os servidores públicos, por intermédio das quais determina

o número de atividades essenciais e estabelece como Crime de Segurança Nacional "a paralisação ou diminuição do ritmo normal do serviço público ou atividade essencial definida em Lei, bem como a paralisação coletiva por parte dos funcionários públicos." A greve dos servidores públicos passa assim a ser enquadrada na Lei de Segurança Nacional, várias vezes invocada neste período para reprimir os grandes movimentos grevistas verificados nas mais diversas categorias (FARIA, 2013, p. 2).

Mesmo com essas medidas restritivas, no quesito greves, o movimento dos trabalhadores públicos registra, ao longo do tempo, iniciativas crescentes. Em 1958 teve a participação de $20 \%$ do total das greves realizadas naquele ano, e em 1963 passou para 58\%, com a participação do funcionalismo vinculado a "autarquias, empresas públicas ou em setores com preços administrados pelo Estado" (NOGUEIRA, 2005, p. I04).

De certo, o ambiente estava propício para a expansão sindical no país, uma vez que no final da década de 1970, a fase da redemocratização e a onda do Novo Sindicalismo propuseram as condições ideais para os movimentos grevistas desses trabalhadores (MASCARENHAS, 2000, 64-65. LOBOS, 1985, pp. 99-102).

Com isso, a primeira greve geral do funcionalismo público federal ocorre em outubro de 1988 , mediante pauta única ( $75 \%$ de reajuste salarial, pagamento imediato da URP - Unidade de Referência de Preços e isonomia salarial dos servidores civis e militares), atingindo, no seu ápice, 17 ministérios, 14 órgãos federais e 3 empresas estatais, totalizando Ioo.ooo grevistas (MASCARENHAS, 2000, 74-75).

No âmbito das universidades federais, "no período de 25 de novembro (1988) a II de janeiro, os (as) Trabalhadores (as) das Universidades pararam suas atividades, por 47 dias de luta, reivindicando melhores salários", porém não há registro de participação dos professores, representados principalmente pela então ANDES (FASUBRA, 2009, p. II. ANDES, p. I).

No ano seguinte, conforme deliberação do II Congresso Nacional dos Servidores Públicos Federais é criada a Intersindical (unidade sindical de amplitude nacional) e deflagrada a segunda greve geral da categoria, sob o comando desta entidade. Nessa greve geral, ocorre a primeira negociação coletiva da categoria com o Governo Federal, diretamente com a Ministra do Trabalho, Dorothéa Werneck, cujo resultado não atendia plenamente as reivindicações, mas chega a termos desejáveis, resultando no final da greve (MASCARENHAS, 2000, 80-82).

Essas duas grandes greves ocorreram nos primeiros anos de vigência da Constituição Federal, tornando-se marco histórico para a nova fase do movimento trabalhista dos servidores públicos. No ano seguinte ao da promulgação, o movimento alcança os serviços públicos federais, estaduais e municipais, realizando $38,2 \%$ do total de greves realizadas naquele ano. "A constituição veio, neste sentido, conformar ao 
corpo das leis sindicais a experiência prática que se impunha como realidade durante toda a década de 80 ". Percebe-se que no pós-CF/88 é estabelecida nova dinâmica de mobilização, com greves longas, negociações complexas, pautas econômicas e políticas, em articulação com o conjunto do movimento sindical. Podemos afirmar que o sentido da liberdade sindical no Estado e da garantia da atividade sindical é bem mais complexo e abrangente (NOGUEIRA, 2005, pp. III, II2; FARIA, 2013, p. 4; NOGUEIRA, 1998, p. 8).

$\mathrm{Na}$ década de 1990, os movimentos dos trabalhadores do setor público sofreram o impacto de planos econômicos, do processo de reestruturação produtiva, das reformas administrativas e do aumento do desemprego, que colocaram o movimento sindical na defensiva. Esse processo de influxo da capacidade de mobilização da categoria fez surgir a identificação de "um novo padrão de ação sindical, no qual a chamada 'estratégia do confronto' teria cedido lugar a uma ação sindical mais institucionalizada, negociadora e propositiva". Traduzindo em números, esse declínio da capacidade de mobilização, resultaram I.298 greves em 1989, em 1990 ocorreram 826 greves e em I991 foram 649. Quanto ao número de grevistas, em 1990 participaram 14.258.304; em 1991 foram 9.139.239. No entanto, em 1996, “o DIEESE registra 62 greves nas empresas estatais e 324 na administração pública, envolvendo um total de 1.069.070 grevistas" (SILVA, 2005, pp. 124;136).

Também nesse sentido, Arnaldo Nogueira (2005, p. 252), apresenta a "radiografia das greves no setor público" mediante números do DIEESE referentes aos movimentos grevistas de 1992 a 1995 , com resultados positivos e ascendentes, com ênfase a 1994 e 1995 , que "indicam tendências de recuperação da capacidade de pressão do movimento sindical". Segundo esse autor os dados demonstram que em 1992 ocorreram 557 greves; em 1993 ocorreram 653; em I994 foram I.034; e em 1995, I.o86. Quanto ao número de grevistas, em 1992, participaram 2.562.385; em 1993, foram 3.595.770; porém, em 1994, caiu para 2.755.619.

Ao analisar esses dados, Nogueira (2005, p. 307-308) infere que critérios políticos e econômicos de Estado impactam diretamente nas atividades sindicais. No campo político, deve-se levar em consideração posturas democráticas ou autocráticas. Para esse autor, "o Estado político brasileiro contém estruturas internas marcadas pela autocracia, pelo autoritarismo e pelo controle de grupos particulares que obstacularizam a construção da esfera pública democrática não burguesa" (NOGUEIRA, 2005, p. 307).

\section{As relações de trabalho dos servidores públicos perante a crise da democracia no Brasil}

Das conquistas advindas pela Constituição para os servidores públicos, notabilizam-se a livre sindicalização e o direito de greve (MATTOS, 2009, p. I25. ANTUNES, 2018, p. 185). Esses dois direitos constitucionais e mais o da negociação 
coletiva se "inter-relacionam como instrumentos de tratamento dos conflitos das relações de trabalho" (FERREIRA et. al., 2012, p. 22).

Como já dito antes, a

Sindicalização dos servidores públicos brasileiros foi por muito tempo alijada do ordenamento jurídico positivo e ainda hoje institutos já consagrados dos trabalhadores da iniciativa privada estão em desenvolvimento na esfera pública, faltando regulamentação apropriada para direitos coletivos do trabalho tal qual a negociação coletiva e a greve" (FERREIRA et. al., 2012, p. 26).

Essa regulamentação apropriada para a negociação coletiva e para o direito de greve no serviço público ainda não ocorreu. Entretanto, em outubro de 2007 o Supremo Tribunal Federal decidiu que seja adotada a lei de greve e de negociação dos celetistas até que o Legislativo nacional efetive lei para atender o setor público (ALCANTARA, 2012, p. 130).

Para Muçouçah (2016, pp. 76-92), “a Constituição Federal de 1988 cometeu falha grosseira: reconheceu os direitos fundamentais de sindicalização e de greve aos servidores públicos, sem, contudo, estabelecer a possibilidade de negociação coletiva de trabalho". Quanto à fundamentação legal, a negociação coletiva no setor público está amparada pela Convenção no ${ }^{\circ}$ 154, da Organização Internacional do Trabalho, ratificada pelo Brasil, conforme Decreto $\mathrm{n}^{\mathrm{O}} \mathrm{I.256}$, de 29 de setembro de 1994, Convenção/OIT no 151 , recomendação/OIT no 159 , promulgadas pelo Decreto $\mathrm{n}^{\circ}$ 7.944/2013. Porém, no que se refere ao Regime Jurídico Único - RJU, dos servidores públicos federais, a lei trouxe a previsão da negociação coletiva, cujo dispositivo foi submetido ao STF, em novembro de 1992, que declarou inconstitucional, alegando que a fixação de vencimentos dos servidores públicos não pode ser objeto de convenção coletiva.

Embora não exista a possibilidade real de que sejam definidas normas eficazes de negociação coletiva "sem o pleno direito do exercício de greve tramita, neste sentido, no Congresso Nacional, o Projeto de Lei no 3831/20154, que pretende suprir a administração pública das normas gerais para a negociação coletiva na administração pública, no qual consta como atores sociais, de forma paritária, os representantes dos servidores e empregados públicos e os representantes do ente estatal respectivo (União, Estados, Distrito Federal e Municípios)" (CARVALHO, 20oI, p 64).

Apesar da inexistência dessas normas, em 2003, foi criada a Mesa Nacional de Negociação Permanente, cujos objetivos e finalidades estão explícitas na Portaria

\footnotetext{
4 Esse PL foi vetado totalmente pelo então Presidente Temer, alegando inconstitucionalidade. "O projeto estaria invadindo a competência legislativa de estados e municípios. Além disso, quaisquer mudanças no regime jurídico de servidor público deveriam ser de iniciativa privativa do presidente da República”. Disponível em: http://www2.camara.leg.br/camaranoticias/noticias/TRABALHO-EPREVIDENCIA/55I289-RELATOR-DEFENDE-DERRUBADA-DO-VETO-A-REGRAS-DENEGOCIACAO-COLETIVA-NO-SERVICO-PUBLICO.html.
} 
SRH/MP № I.132, de 2I de julho de 2003, editada sob o prisma da democratização das relações de trabalho e das soluções dos conflitos por meio de acordos (BRASIL, 2003).

Por outro lado, há que se levar em consideração o desafio dessa regulamentação, por força da necessidade de garantir a institucionalização de um processo democrático, transformador e de consenso, diante de uma realidade de conflito. Democrático, porque possibilita o diálogo a todas as partes envolvidas, necessariamente de forma paritária. Transformador, porque é de se esperar o fim de um conflito e o restabelecimento de uma boa relação de trabalho. E, de consenso, porque uma boa negociação é a que resulta de um bom acordo para todas as partes, não a que resulta em desacordo ou um acordo desvantajoso. (LOBOS, 1985, p. 179)

No que concerne à regulamentação do direito de greve no setor público, a mais recente iniciativa legal tramita no Senado Federal. Porém, o projeto (PLS 375/2018) de autoria do senador Dalírio Beber (PSDB -SC), está parado desde dezembro de 2018, na Comissão de Constituição e Justiça'5.

\section{As relações de trabalho dos servidores públicos: cenários e perspectivas}

As relações de trabalho dos servidores públicos ainda carecem de regulamentações infraconstitucionais de modo a completar o tripé dessas relações: o direito de greve e de negociação coletiva, somados à livre sindicalização já garantida na própria constituição. Quesitos em que os trabalhadores da iniciativa privada têm normas e dispositivos na CLT que contemplam essas regulamentações, o que não ocorre em relação aos servidores públicos. Estes têm que adotar, por analogia e no que couber, por força de decisão do STF, a lei de greve dos trabalhadores privados, sem, no entanto, terem conseguido a regulamentação da negociação coletiva da categoria ${ }^{6}$.

Lamentavelmente, o avanço vislumbrado pela categoria nesse quesito obteve êxito no Congresso Nacional, mas foi frustrado, em 2017, pelo então presidente Temer, que vetou integralmente o projeto de lei. Em grande medida, essa decisão decorre da nova política econômica adotada pelo governo Temer, que Arouca (2019, p. 493) chama de "neocapitalismo", no qual impera o Estado mínimo e o rigor fiscal, cuja implementação precisa superar as barreiras impostas pelos movimentos sindicais, devido a sua capacidade de mobilização de massas.

Em nome desses compromissos com o capital, além das diversas medidas do Poder Executivo para retirada de direitos e precarização do trabalho, como a reforma trabalhista e a reforma da previdência, há também muitas medidas de ataques aos movimentos dos trabalhadores, inclusive pelo Poder Judiciário por intermédio da decisão do Supremo Tribunal Federal, determinando o corte de ponto dos servidores

\footnotetext{
5 Fonte: https://www25.senado.leg.br/web/atividade/materias/-/materia/134198

${ }^{6}$ http://www.stf.jus.br/portal/cms/verNoticiaDetalhe.asp?idConteudo=75355, acesso em 16/12/ 2019 . 
públicos grevistas ${ }^{7}$, resultando na desmobilização generalizada da categoria. Nessa mesma linha, o atual governo cria obstáculos para o desconto em folha das mensalidades sindicais, configurando forte investida contra a principal fonte de financiamento dessas entidades.

Evidente que tudo isso atinge as forças sindicais dificultando a resistência às medidas e projetos econômicos do Governo, segundo as suas prioridades, em detrimento dos direitos sociais, civis e políticos, conquistados ao longo da história. Exemplo disso, no governo Temer, as centrais sindicais mobilizam muitas caravanas do interior do país para Brasília contra a então PEC no $24 \mathrm{I}$, conhecida como a PEC dos Gastos ou a PEC da Morte (EC. № 95/2016), contra a lei das terceirizações e contra as reformas trabalhista e previdenciária ${ }^{8}$.

Nessas grandes manifestações, na capital federal, os trabalhadores são recebidos pelas forças militares, com balas de borracha, bombas de gás lacrimogênio e bombas de efeito moral. Em resposta, são incendiados veículos de empresas de comunicação e invadidos prédios públicos ${ }^{9}$. $\mathrm{Na}$ avaliação do movimento sindical, a reforma da previdência não avançou no governo Temer graças a essas mobilizações nacionais rumo à Brasília, não ocorrendo o mesmo sucesso com relação à $\mathrm{PEC}$ dos gastos, à lei das terceirizações e à reforma trabalhista.

É notável, também, que essas sucessivas derrotas demonstram que as organizações dos trabalhadores não estão fortes o suficiente para impedir o avanço desses grandes projetos do Executivo, resultando na inércia perante a reforma da previdência aprovada com tranquilidade no governo atual.

Enquanto isso, as organizações sindicais buscam estratégias para superarem esses desafios, para autofinanciarem-se, para reterem e ampliarem seus quadros de filiados, para aperfeiçoar a capacidade de mobilização das categorias com vistas às manifestações de ruas, para encararem as ameaças do atual governo e, principalmente, obterem êxito nas suas pautas de lutas.

É diante deste contexto que o movimento sindical precisa exercer o seu papel de representar e fazer valer as expectativas e necessidades dos trabalhadores, de mobilizá-los, e buscar unidade junto a outras forças sociais e políticas. Ao conseguir esse êxito, o movimento terá superado todos os desafios e, mais uma vez, a exemplo das diversas fases apontadas neste trabalho, reinventar-se-á, ressurgirá forte e capaz de dar prosseguimento aos seus propósitos e às conquistas tão caras à classe trabalhadora. Desse modo, infere-se que quanto mais vivência democrática nas relações de trabalho e nos espaços políticos de atuação dos sindicatos, mais conquistas

\footnotetext{
7 http://agenciabrasil.ebc.com.br/geral/noticia/20ı6-ı/stf-valida-corte-de-ponto-de-servidorespublicos-em-greve, acesso, 16/12/2019.

8 https://wwwi.folha.uol.com.br/poder/2017/o5/1886639-sindicatos-e-movimentos-sociais-faraomanifestacao-contra-temer.shtml, acesso em 16/12/2019.

9 https://www.brasildefato.com.br/2017/o5/25/com-20o-mil-manifestantes-movimentos-popularescomemoram-exito-do-ocupa-brasilia/, acesso em I6/12/2019.
} 
ocorrerão para os trabalhadores e para a população em geral. Porém, na crise política atual, essas organizações têm, mediante a unidade com outras entidades similares e movimentos sociais, manifestado-se e lutado na medida do possível, com raros êxitos devido às forças neocapitalistas que têm conseguido limitar as ações, forçando o movimento sindical à descoberta de novas estratégias de sobrevivência e de enfrentamento dos desafios internos e externos.

De todos os desafios, o maior é reconquistar a confiança de suas bases, para daí se fortalecer financeiramente e em números de trabalhadores necessários para as mobilizações e para a correlação de forças perante o governo.

$\mathrm{O}$ quesito confiança foi objeto de pesquisa recente, realizada pelo grupo XP Investimentos, através da qual se pode uma ideia do nível de confiança da população em relação ao sindicalismo (Gráfico I), bem como as variações dessa percepção ao longo dos períodos pesquisados (Gráficos 2 e 3).

Gráfico I: Confiança nas Instituições

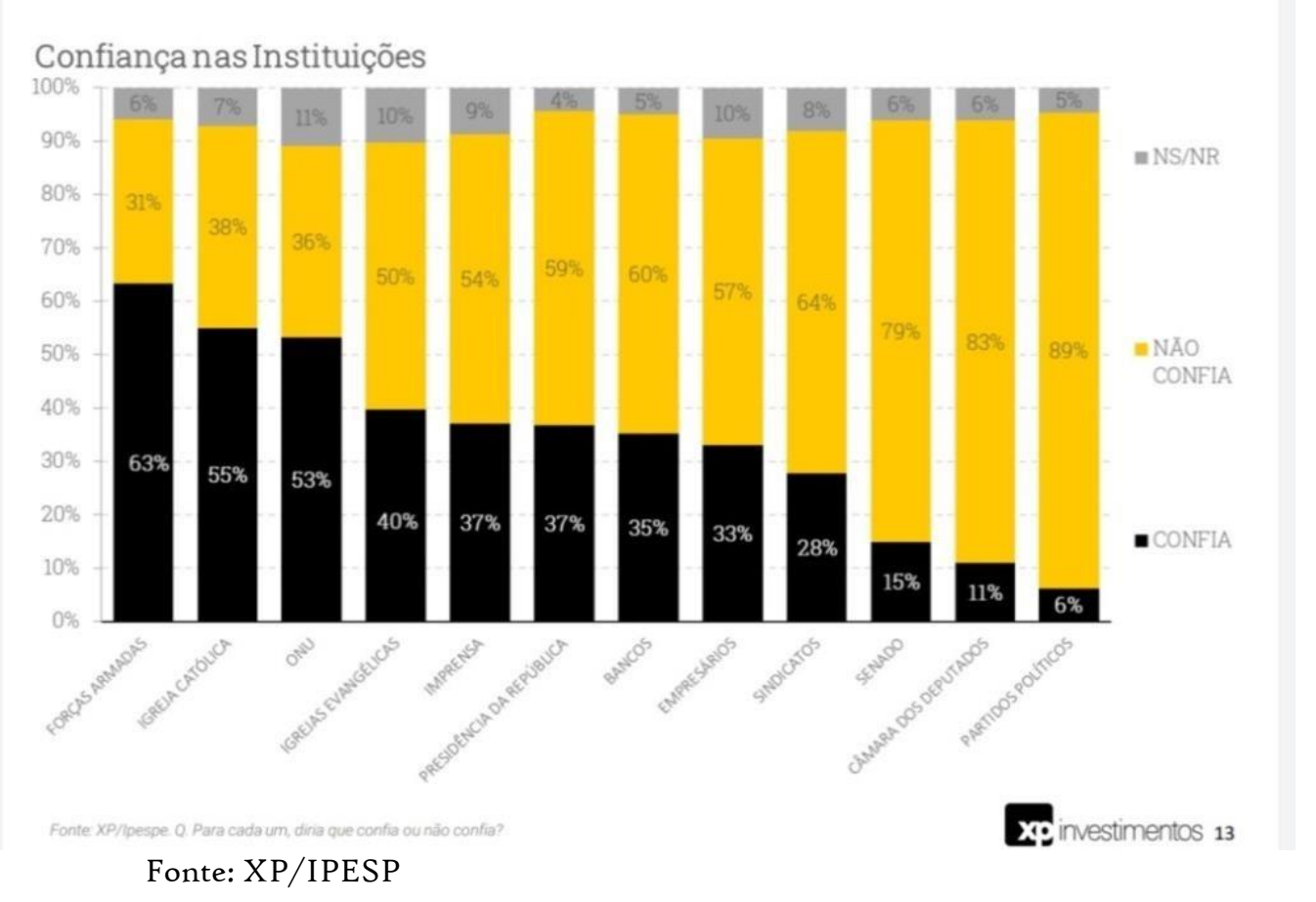

Segundo estes dados, os sindicatos estão com os menores níveis de confiança, juntamente com outras forças políticas, que, diga-se de passagem, são as principais forças representativas da classe trabalhadora (sindicatos) e da população em geral (Congresso Nacional e partidos políticos).

Por outro ângulo, a pesquisa demonstra, conforme Gráficos 2 e 3, que há oscilação dessa percepção popular, ao longo dos dois anos. 
Gráfico 2: Confiança no tempo: Confia

\section{Confiança no tempo: CONFIA}

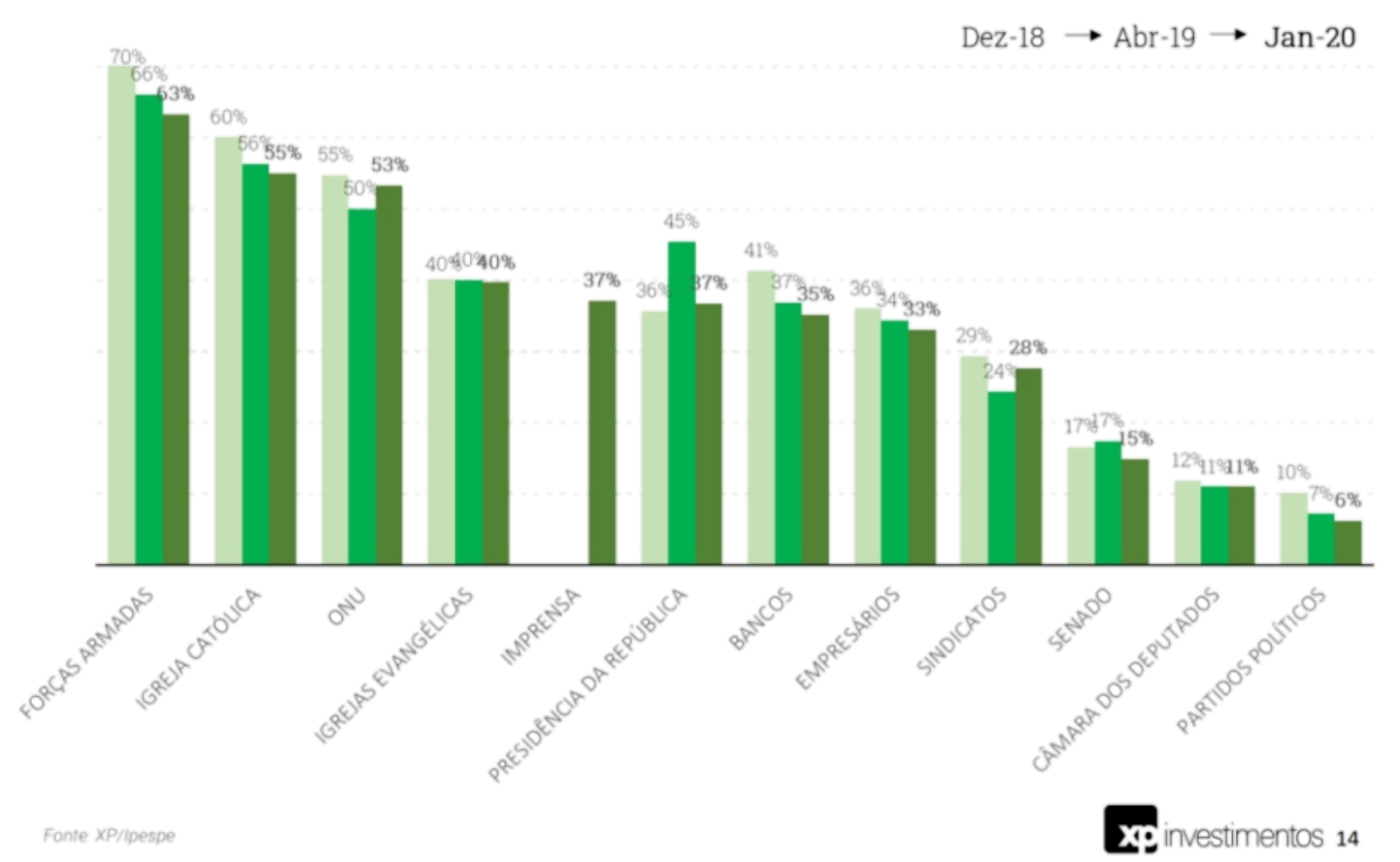

Fonte: XP/IPESP

A redução de confiança demonstrada de dezembro de 2018 (29\%) para abril de 2019 (24\%) foi quase revertida em janeiro de 2020 (28\%), ao passo que a presidência da República teve a sua confiabilidade aumentada de $36 \%$ para $45 \%$, porém diminuída para $37 \%$ em 2020, sem levar em conta a margem de erro.

Com esse mesmo recorte analítico, percebe-se que a desconfiança oscila em relação a essas duas instituições, conforme demonstra o Gráfico 3. 


\section{Confiança no tempo: NÃO CONFIA}

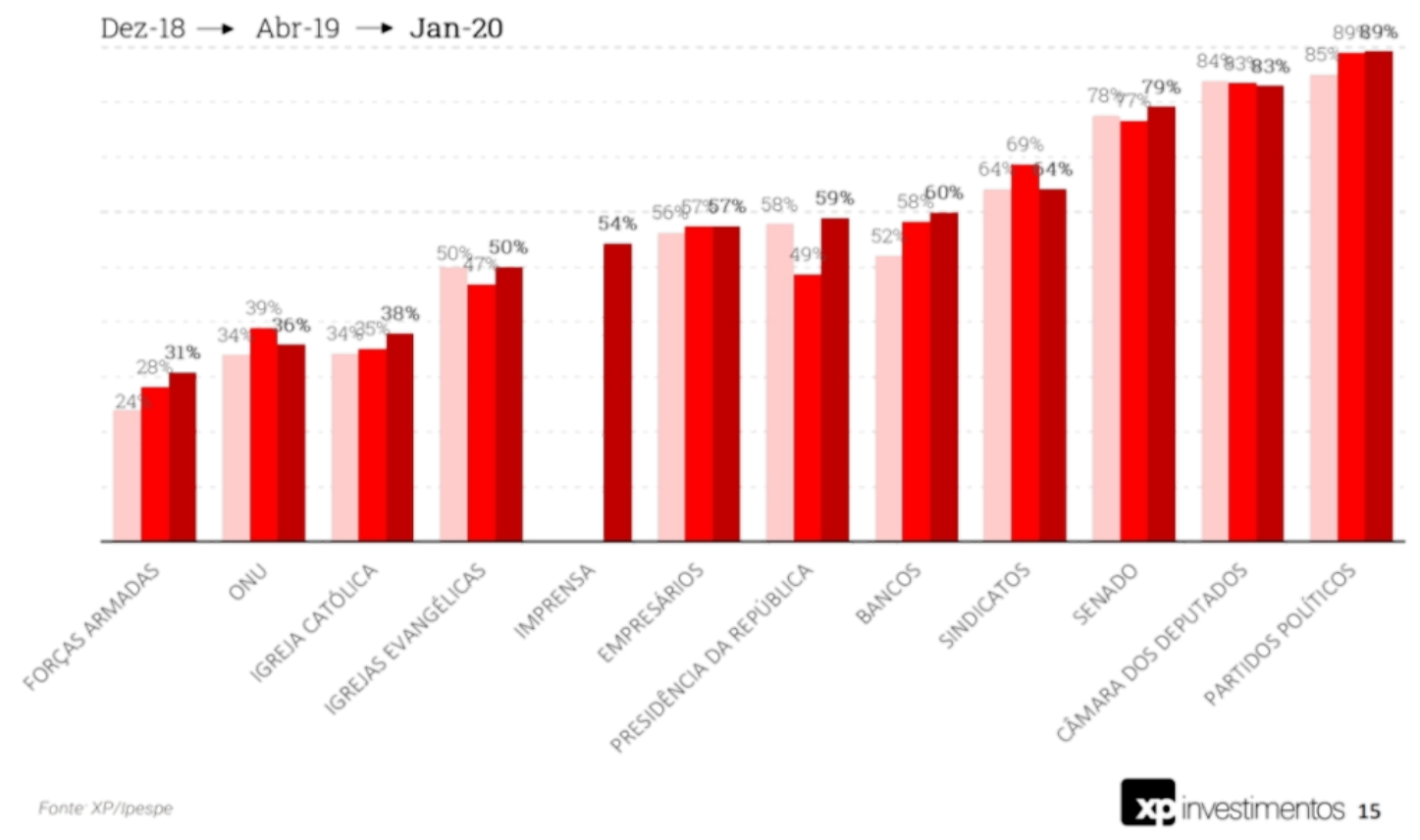

Fonte: XP/IPESP

Embora estejam emparelhados no mesmo grupo dos menos confiáveis, os sindicatos tiveram uma oscilação positiva no período de abril de 2019 a janeiro de 2020, quase que recuperando a credibilidade inicial.

Outro fato demonstrado, comparativamente com a Presidência da República, é que as oscilações são inversamente proporcionais, ou seja, na medida em que cai a confiança na Presidência da República aumenta no sindicalismo.

\section{Considerações finais}

O sindicalismo dos servidores públicos brasileiro traz consigo uma realidade peculiar motivada pelo longo período de proibição, no qual se manifestava como associação recreativa. Mas, ao mesmo tempo e pelo mesmo motivo, não passou pelas pressões e manobras políticas de Estado a que foram submetidos os demais sindicatos, na Era Vargas e no decorrer das ditaduras.

Ele surgiu numa fase importante na política brasileira, a redemocratização. Época em que nascia o Novo Sindicalismo, cuja principal característica é a rejeição 
dessas pressões e manobras políticas de cooptação e o propósito de que seja estabelecido o sindicalismo livre, autônomo e combatente.

Isto demonstra que a vitalidade do sindicalismo de um modo em geral está diretamente ligada à liberdade (individual e coletiva) e a democracia sindicais, sem as quais há desestruturação, deslegitimação, desorganização, falta de confiança e, muitas vezes, clandestinidade, como ocorreu no período anterior à Constituição Federal/r988.

Mas sem dúvidas, é a partir da nova república, com governos civis e com a nova Constituição Federal, que a democracia sindical é parcialmente restabelecida, principalmente com as garantias de liberdade e demais direitos para as organizações e para os trabalhadores, inclusive para os trabalhadores dos servidores públicos. Faltando-lhe até os dias atuais normas legais que estabeleçam definitivamente as práticas de greve e de negociação coletiva, completando o tripé do sindicalismo do setor público.

Este estudo, na sua totalidade, demonstra que a democracia sindical e a capacidade de mobilização dos trabalhadores nunca foram estáveis, porém sempre ressurgem com muita força e cumprem o seu importante papel de agente social na representatividade da classe trabalhadora das suas bases.

Nesse sentido, quanto mais estudos acadêmicos houver sobre as relações de trabalho no setor público, menos lacunas epistemológicas e históricas permanecerão e mais oportunidades surgirão para que finalmente ocorra a regulamentação da negociação coletiva e da greve nesse setor.

\section{Bibliografia}

ANTUNES, Ricardo. O privilégio da servidão: o novo proletariado de serviços na era digital. ı ${ }^{\text {a }}$ Ed. São Paulo: Boitempo, 2018.

AROUCA, José Carlos. Organização sindical no Brasil: passado - presente - futuro (?). $2^{\mathrm{a}}$ ed. São Paulo: LTr, 2019. E-book, Edição do Kindle.

AZEVEDO, Luiz. Sindicalismo sob ataque. Unidade e democracia na organização sindical. Florianópolis, SC: Insular Livros, 2019.

BOITO, Armando. O sindicalismo de Estado no Brasil: uma análise crítica da estrutura sindical. Campinas: Editora da UNICAMP: São Paulo: Hucitec, 1991.

BRASIL. Constituição da República Federativa do Brasil, de o5 de outubro de 1988. Disponível

em: http://www.planalto.gov.br/ccivil_03/constituicao/constituicao.htm. Acesso em: i6 dez. 2019. 
BRASIL. Lei no 7.783 , de 28 de junho de I.989. Dispõe sobre o exercício do direito de greve, define as atividades essenciais, regula o atendimento das necessidades inadiáveis da comunidade, e dá outras providências. Disponível em: http://www.planalto.gov.br/ccivil_03/leis/17783.HTM. Acesso em: 19 jan. 2020.

BRASIL. PL n⿳0 3.831/2015. Estabelece normas gerais para a negociação coletiva na administração pública direta, nas autarquias e nas fundações públicas dos poderes da União, dos Estados, do Distrito Federal e dos Municípios. Disponível, em: https://www.camara.leg.br/proposicoesWeb/fichadetramitacao?idProposicao $=20578$ I8. Acesso em 19 jan. 2020.

BRASIL. Portaria no 1.132, de 2i de julho de 2003. Aprovar o Regimento Institucional da Mesa Nacional de Negociação Permanente - MNNP. Disponível em: https://pesquisa.in.gov.br/imprensa/servlet/INPDFViewer?jornal $=\mathrm{I} \&$ pagina $=5 \mathrm{I} \& \mathrm{~d}$ ata $=22 / 07 / 2003 \&$ captchafield $=$ firstAccess. Acesso em 23 mai. 2021.

CAVALCANTE, Laís Siqueira Ribeiro. Cenário pós-ditaduras cívico-militares: uma análise comparativa entre Argentina e Brasil. Democracia na América Latina [recurso eletrônico]: democratização, tensões e aprendizados / Maria Victória Espiñeira González, Danilo Uzêda da Cruz, organizadores. - Buenos Aires: CLACSO; Feira de Santana, Zarte, 2018. pp. 156-166.

CONCEIÇÃO, Maria da Consolação Vegi da. A greve no serviço público: elementos conceituais e o debate em torno da sua regulamentação. Âmbito Jurídico, Rio Grande, $\mathrm{XI}, \quad$ n. 52, abr. 2008. Disponível em: <http://www.ambitojuridico.com.br/site/index.php?n_link=revista_artigos_leitura\&artigo_id $=2685>$. Acesso em I9 jan. 2020.

CRIVELLI, Ericson. Democracia sindical no Brasil. Dissertação de mestrado apresentada ao Departamento de Ciência Política do Instituto de Ciências Políticas e Sociais da Universidade Estadual de Campinas. UNICAMP, 20oo. Disponível em: http://repositorio.unicamp.br/bitstream/REPOSIP/278793/r/Crivelli_Ericson_M.p df. Acessado em I4/10/2019. Acesso em i6 dez. 2019.

DELGADO, Mauricio Godinho. Direito Coletivo do Trabalho. São Paulo: Revista dos Tribunais, 2011.

FARIA, Maurício Sardá de. Brasil: o "novo sindicalismo" no setor público. La question sociale, I-6. 2004. Acesso em 24 de Out de 2013, disponível em http://www.vivelasociale.org/revue-la-questionsociale/html/LQS/LQS_I/por_QSI_II_bresil.pdf. Acesso em i9 jan 2020. 
FERRARI, Irany; NASCIMENTO, Amauri Mascaro; MARTINS FILHO, Ives Gandra da Silva. História do trabalho, do direito do trabalho e da justiça do trabalho. $3^{\text {a }}$ ed. São Paulo, LTr, 201 .

GUEDES, Cezar. Os trabalhadores no setor público brasileiro: prática sindical, conquistas e armadilhas. Coletânea Mundo do trabalho: crise e mudança no final do século. Fundação de Economia de Campinas. Organizadores: Carlos Alonso Barbosa de Oliveira, Jorge Eduardo Levi Mattoso, José Francisco Siqueira Neto, Marcio Pochmann, Marco Antonio de Oliveira. São Paulo: Página Aberta. 1994.

LEMOS, Tayara Talita; DE ALMEIDA JUNIOR, Benedito Silva; DE MELLO, Larissa Fernandes Ranieri. O povo contra a democracia: o problema da abstenção dos indivíduos em relação ao exercício de seus direitos políticos. Revista Eletrônica Direito e Política, Programa de Pós-Graduação Stricto Sensu em Ciência Jurídica da UNIVALI, Itajaí, v.Io, n.4, $3^{\text {o }}$ quadrimestre de 2015. Disponível em: www.univali.br/direitoepolitica - ISSN 1980-7791. Acesso em i9 jan. 2020.

LOBOS Troncoso, Júlio Alejandro. Sindicalismo e negociação. $2^{2}$ ed. - Rio de Janeiro: José Olympio, 1985.

MASCARENHAS, Ângela Cristina Belém. Desafiando o Leviatã: Sindicalismo no setor público. Campinas, SP: Alínea, 2000.

MATTOS, Marcelo Badaró. O Sindicalismo brasileiro após 1930 (Descobrindo o Brasil). Zahar, 2003. Edição do Kindle

MATTOS, Marcelo Badaró. Trabalhadores e sindicatos no Brasil. I ${ }^{\text {a }}$ Ed. São Paulo: Expressão Popular, 2009.

MORAIS, Jorge Ventura de. Trabalhadores, Sindicatos e Democracia: um ensaio bibliográfico sobre democracia sindical. Disponível em: http://www.anpocs.com/index.php/bib-pt/bib-4I/463-trabalhadores-sindicato-edemocracia-um-ensaio-bibliografico-sobre-democracia-sindical/file. Acessado em: I4 dez. 2019.

MUÇOÇAH, Renato de Almeida de Oliveira. O direito dos servidores públicos à negociação coletiva. RDU, Porto Alegre, v. I2, no 68, 2016, 73-94) Disponível em: https://portal.idp.emnuvens.com.br/direitopublico/article/view/2586/pdf. Acesso em: 19 jan. 2020.

NOGUEIRA, Arnaldo José França Mazzei. A liberdade desfigurada: a trajetória do sindicalismo no setor público brasileiro. 2⿳亠 Ed. São Paulo: Expressão Popular, 2005. 
NOGUEIRA, Arnaldo José França Mazzei. Emergência e Crise do Novo Sindicalismo no Setor Público Brasileiro. XXII Encontro Anual da ANPOCS. São Paulo. 1998. Disponível em: https://anpocs.com/index.php/encontros/papers/22encontro-anual-da-anpocs/gt-20/gt18-16/5182-anogueira-emergencia/file. Acesso em: I9 jan 2020 .

SILVA, Antonio Alfreu da. Sindicato e democracia: uma proposta para um modelo sindical livre. Fortaleza, CE: UNIFOR, 2016.

SILVA, Sidney Jard da. Companheiros servidores [livro eletrônico]: o sindicalismo do setor público na CUT. SciELO - São Bernardo do Campo: EdUFABC, 2015.

XP/IPESP. Pesquisa de opinião. Cobertura: Nacional. Metodologia: Entrevistas telefônicas realizadas por operadores. Número de entrevistas: Iooo. Margem de erro: 3,2 pontos percentuais. Período de coleta: 13 a is de Janeiro de 2020 https://conteudos.xpi.com.br/politica/relatorios/pesquisa-xp-janeiro-2020-primeirapesquisa-do-ano/. Acesso em 19 jan 2020. 